\title{
An Exploration of the Perceived Usefulness of the Introductory Statistics Course and Students' Intentions to Further Engage in Statistics
}

Rossi A. Hassad

Mercy College, New York, USA, Rhassad@mercy.edu

Follow this and additional works at: https://digitalcommons.usf.edu/numeracy

Part of the Medicine and Health Sciences Commons, and the Psychology Commons

\section{Recommended Citation}

Hassad, Rossi A.. "An Exploration of the Perceived Usefulness of the Introductory Statistics Course and Students' Intentions to Further Engage in Statistics." Numeracy 11, Iss. 1 (2018): Article 7. DOI: https://doi.org/10.5038/1936-4660.11.1.7 


\title{
An Exploration of the Perceived Usefulness of the Introductory Statistics Course and Students' Intentions to Further Engage in Statistics
}

\begin{abstract}
Students' attitude, including perceived usefulness, is generally associated with academic success. The related research in statistics education has focused almost exclusively on the role of attitude in explaining and predicting academic learning outcomes, hence there is a paucity of research evidence on how attitude (particularly perceived usefulness) impacts students' intentions to use and stay engaged in statistics beyond the introductory course. This study explored the relationship between college students' perception of the usefulness of an introductory statistics course, their beliefs about where statistics will be most useful, and their intentions to take another statistics course. A cross-sectional study of 106 students was conducted. The mean rating for usefulness was 4.7 (out of 7), with no statistically significant differences based on gender and age. Sixty-four percent reported that they would consider taking another statistics course, and this subgroup rated the course as more useful $(p=.01)$. The majority $(67 \%)$ reported that statistics would be most useful for either graduate school or research, whereas $14 \%$ indicated their job, and $19 \%$ were undecided. The "undecided" students had the lowest mean rating for usefulness of the course $(p=.001)$. Addressing data, in the context of real-world problem-solving and decision-making, could facilitate students to better appreciate the usefulness and practicality of statistics. Qualitative research methods could help to elucidate these findings.
\end{abstract}

\section{Keywords}

Statistics Education, Statistical Literacy, Perceived Usefulness, Introductory Course, Quantitative Reasoning

\section{Creative Commons License}

\section{c) (7) (8)}

This work is licensed under a Creative Commons Attribution-Noncommercial 4.0 License

\section{Cover Page Footnote}

Rossi A. Hassad is a professor in the School of Social and Behavioral Sciences, Mercy College, New York. His areas of expertise include statistical literacy, quantitative reasoning, and evidence-based practice in the health and behavioral sciences. 


\section{Introduction and Rationale}

Statistical literacy is now recognized by most disciplines as a necessary competency for informed and engaged citizenship (Wallman 1993; Engel 2017), a competency that encompasses success in college and the workplace and includes evidence-based decision-making. Focusing on statistical literacy, however, represents a major paradigm shift in the way teaching and learning of introductory statistics have been conceptualized and implemented (Hassad 2011; Sabbag and Zieffler 2015). The change underway can be characterized as a move from the traditional, behaviorist (instructor-centered) pedagogy to a more reform-based, constructivist (student-centered) approach. In the latter, the students are considered an equal partner in the teaching and learning process, and their courserelated beliefs, emotions, and intentions (generally viewed collectively as attitude) are recognized as pivotal to effective teaching and learning (Sproesser, Engel, and Kuntze 2016). Constructivist pedagogy emphasizes the learning process, including cognitive style, motivation for learning, and construction of meaning, which can facilitate deep and conceptual learning, and hence transferrable knowledge and skills.

In this regard, the introductory statistics course has garnered much attention from the statistics education reform movement, specifically in terms of adapting the curriculum to be more meaningful and practical, by incorporating active learning strategies, including the use of authentic assessments (GAISE 2016). Moreover, there is a consensus among educators that the focus of the introductory course should be to develop statistical literacy, which encompasses statistical reasoning and thinking. Statistical literacy is typically defined as: "People's ability to interpret and critically evaluate statistical information and data-based arguments appearing in diverse media channels, and their ability to discuss their opinions regarding such statistical information" (Gal 2000 as cited in Rumsey 2002, 2). Furthermore, an understanding of the data context (Hassad 2013), as well as "a feel for how to assess real-life data" (Watkins, Scheaffer, and Cobb 2010, xvii), are key to developing statistical literacy. In other words, the students' attitude or mindset is relevant.

Students' attitude toward statistics is well-established as a predictor of academic success (Schau and Emmioglu 2012). The Survey of Attitudes Toward Statistics (SATS) is considered the foremost instrument for measuring student attitude (Gundlach et al. 2015), and it possesses very good psychometric properties (reliability and validity). Indeed, the SATS has shown that attitude accounts for about 14 percent of the variance in student achievement (Nolan et al. 2012), implying that although attitude might be necessary, it is not sufficient to explain the variance in student success. While there is much variability in how 
attitude is conceptualized, operationalized, and interpreted, a salient and consistent component in this context is students' perceived value or usefulness of statistics (Nolan et al. 2012); this perception underpins motivation to learn and apply the knowledge and skills acquired, including pursuing further studies in statistics. Moreover, the limited published research shows a tendency for students to be disinclined to use statistics in the field they hope to be employed, or to take another statistics course (Ramirez and Bond 2014); this behavior can be counterproductive to personal and professional success - and the advancement of the discipline of statistics. Related research in statistics education has focused almost exclusively on the role of attitude in explaining and predicting academic learning outcomes; therefore, there is a paucity of research evidence on how attitude (particularly perceived usefulness) influences students' intentions to use and stay engaged in statistics beyond the introductory course.

\section{Theoretical and Conceptual Framework}

The expectancy-value theory (Wigfield, Tonks, and Eccles 2004) and the selfdetermination theory (Ryan and Deci 2000) are conceptual models that provide insight into the role of beliefs and attitudes in the motivational underpinning of learning. Specifically, the expectancy-value theory posits that students' expectancies or beliefs regarding the usefulness of the course, and their likelihood of being successful, will determine how much value or importance they attribute to the course, their interest in the material, and the extent to which they engage in the discipline. And with reference to the self-determination theory, perceived competence or self-efficacy (the belief in one's capability to be successful) is a key determinant of motivation to learn. Moreover, there is a growing body of evidence that supports a strong association between self-efficacy and perceived usefulness (Wong, Teo, and Russo 2012).

Together, these models can help to explain and predict the quality of learning outcomes, and the likelihood that students will use and develop the knowledge and skills acquired from the introductory course. As noted by Schau and Emmioglu $(2012,92)$, "Students will not employ statistics in life, in their work, or in other courses unless they believe it is useful. They will use statistics only if they believe that they can do statistics." For the purpose of this paper, perceived usefulness refers to beliefs about the value of statistics to personal, school, and professional life.

\section{Objective}

This study explored the variability in students' perceptions of the usefulness of an introductory statistics course based on their beliefs about where statistics will be 
most useful, their intentions to take another statistics course, as well as age and gender.

\section{Methodology}

This cross-sectional study was conducted with 106 undergraduate students from the humanities and behavioral sciences, including psychology. The students came from three different Colleges and were taught by the same instructor in the Fall 2016 semester. An in-class questionnaire was administered to all students at the end of the introductory statistics course and before the final examination; it ascertained the following in addition to age and gender: (1) How would you rate the usefulness of this course? (2) Where do you believe the statistics knowledge and skills acquired from this course will be most useful? (3) Would you consider taking another statistics course? A single-item measure (with a 7-point response scale) was used for a global rating of the usefulness of the course.

The statistics course was designed in accordance with the American Statistical Association Guidelines for Assessment and Instruction in Statistics Education (GAISE 2016). The material encompasses common statistical methods and their applications within the disciplines. The course covers both descriptive and inferential statistics (in that order) and includes types of data, levels of measurement, frequency distributions, graphs, measures of central tendency, measures of variability, cross-tabulation, sampling, $z$-score and the normal distribution, as well as tests of hypothesis such as the $t$-test, ANOVA, linear correlation and regression, and chi-square. Effect size, study designs (observational and experimental) and related concepts (including association, causation, confounding, and interaction) are also addressed, and the IBM-SPSS software is used for data analysis. While the mathematical underpinning of each statistical method is addressed, the course emphasizes concepts over calculations, with a focus on telling the story of the data by way of oral presentations and written narratives. Critiquing of quantitative research articles is also included, and, in order to further demonstrate the integration and application of knowledge and skills, students are required to complete a small-group project in which they explore and analyze primary or secondary data, and submit a structured written report.

Data entry and analysis for this study were conducted using SPSS version 24, and both descriptive and inferential statistical analyses were performed. Specifically, the independent samples $t$-test and one-way ANOVA (with post-hoc analysis, Bonferroni correction, and effect size), and an alpha level of .05 were used to check for subgroup differences regarding perceived usefulness of the introductory statistics course. Consistent with ethical guidelines, the analysis was limited to the combined sample so as to protect the identity of the institutions. 


\section{Results}

The sample $(N=106)$ was predominantly female $(80 \%)$ and young, with $90 \%$ being 18-25 years of age. The percent distribution of males and females in this study reflects a wider gap than the trend for the general student population in the United States. The mean rating for usefulness of the introductory statistics course was 4.7 on a 7-point scale where higher scores are more favorable (Table 1), and there were no statistically significant differences based on gender and age. Sixtyfour percent reported "yes" to whether they would consider taking another statistics course (Table 2), and that group was more likely than those who reported "no" to rate the statistics course as more useful (Table 3 ).

Regarding the areas in which students believed that statistics will be most useful (Table 2), almost equal proportions reported research (32\%) and graduate school (35\%), whereas $14 \%$ indicated their job, and $19 \%$ were undecided. The "undecided" students had the lowest mean rating for usefulness of the statistics course, which was significantly different from the mean ratings for the other response categories (Table 1).

Table 1.

Comparison of students' rating of the usefulness of the introductory statistics course by their response to where statistics will be most useful $(N=105)$.

\begin{tabular}{llll}
\hline $\begin{array}{l}\text { Where do you believe } \\
\text { statistics will be most useful? }\end{array}$ & $N$ & Mean* & SD \\
\hline Graduate School & 37 & 5.08 & 1.26 \\
My Job & 15 & 5.13 & 1.19 \\
Research & 33 & 4.70 & 1.24 \\
Undecided & 20 & 3.50 & 1.28 \\
Total & 105 & 4.67 & 1.36 \\
\hline Usefulness was rated using a single item with a 7-point \\
response scale, where higher ratings are more favorable. \\
*F $(3,101)=7.93, \mathrm{p}=.001$; Eta Squared = .19, Tukey's HSD \\
was used for multiple pairwise comparisons.
\end{tabular}

Table 2.

Percent response to survey questions $(N=106)$.

\begin{tabular}{lcc}
\hline $\begin{array}{l}\text { Where do you believe statistics } \\
\text { will be most useful? }\end{array}$ & $N$ & $\%$ \\
\hline Graduate School & 37 & 35 \\
My Job & 15 & 14 \\
Research & 34 & 32 \\
Undecided & 20 & 19 \\
\hline
\end{tabular}

Table 3.

Comparison of students' rating of the usefulness of the introductory statistics course by their intention to take another statistics course $(N=105)$.

Would you consider taking another statistics $N$ Mean* ${ }^{*}$ SD

Would you consider taking another statistics course?

\begin{tabular}{lll}
\hline Yes & 68 & 64 \\
No & 38 & 36 \\
\hline
\end{tabular}

\begin{tabular}{lrrr} 
course? & 67 & 4.94 & 1.15 \\
\hline Yes & 38 & 4.18 & 1.57 \\
No & $*_{\mathrm{t}}(103)=2.6, \mathrm{p}=.012$ (based on Welch's adjustment \\
for unequal variances), Cohen's $d=.52$.
\end{tabular}




\section{Discussion and Implications}

This study explored the association between college students' rating of the usefulness of an introductory statistics course, their beliefs about where statistics will be most useful, and their intentions to take another statistics course. In general, students rated the course as moderately useful, with a mean of 4.67 (based on a single item with a 7-point response scale), which is comparable to a mean score of 4.72 (for perceived value) reported by Schau and Emmioglu (2012) using the multi-item SATS (Survey of Attitudes Toward Statistics) scale. Other studies have noted considerably lower levels of perceived usefulness or value. For example, Ramirez and Bond (2014) reported that only $20 \%$ of students (35 out of 175) who completed an introductory statistics course were neutral or expressed some degree of usefulness for the course. One plausible explanation for these mixed reports is the lack of consistency in how attitude and its components (including perceived usefulness) are measured and interpreted; this factor could limit comparability across studies (Nolan, Beran, and Hecker 2012).

Notably, favorable levels of perceived usefulness (and attitude, in general), are usually associated with active learning, or student-centered pedagogical approaches involving the use of real-world applications (Evans 2007; Carlson and Winquist 2011; Hassad 2015). While the statistics course that was rated in the current study used a predominantly active learning approach, the research design was cross-sectional (non-experimental); that is, information was obtained at one point in time only (at the end of the course). Accordingly, although it seems reasonable to attribute the positive ratings of usefulness to the active learning approach, the evidence does not allow for a conclusive determination, given the absence of baseline data or evidence from a similar group of students (who received traditional pedagogy) for comparison.

Additionally, it is not surprising that in response to the question Where do you believe statistics will be most useful?, the highest proportions were graduate school (35\%) and research (32\%). The former is usually a natural preoccupation and the next step for most undergraduate students at this stage, and both areas are generally emphasized in a constructivist-based or active learning course (in terms of value and real-world applications). Of some concern, however, is that $19 \%$ of the students were "undecided" about where statistics would be most useful, and this subgroup rated the usefulness of the introductory statistics course significantly lower than the rest of the students. This result does not necessarily mean that these "undecided" students were lacking in their understanding of the course material. Rather, it could be that they did not consider statistics to be relevant and useful to their future. Indeed, this possibility needs to be further 
explored, given that an overarching goal of the introductory statistics course should be to facilitate students to recognize and appreciate the usefulness of statistics, in particular, how it relates to everyone, in terms of everyday problemsolving and decision-making, toward informed and active citizenship.

Another concern is the proportion of students $(36 \%)$ who reported that they would not consider taking another statistics course, and this subgroup rated the usefulness of the introductory course significantly lower than those who reported "yes." Interpreting this result is complex, because, although it is hoped that students will further their knowledge and skills in statistics and contribute to the discipline, their response will quite likely be influenced by their future plans and intentions in terms of work, graduate school, etc. Therefore, these students may be satisfied with the introductory statistics course and not see the need for another statistics course, or they may be ambivalent about the relevance and usefulness of formal statistics to their future. And of course, the negative response could quite possibly reflect that these students were not satisfied with the course material, did not have a positive experience, and were therefore less inclined to recognize and appreciate the usefulness of statistics, and consider pursuing another statistics course. Notwithstanding, other studies have reported much less favorable findings in this regard.

For example, Ramirez and Bond (2014) reported that 66\% $(N=64)$, and 65\% $(N=111)$ of students who took a project-based course (where the project was 20 percent of the final grade) and a hybrid course (traditional lecture and online), respectively, were not likely to take another statistics course. It is worth observing that these two course formats seem intended to compare different pedagogical approaches (active learning versus traditional). However, while a project-based course usually implies an active learning course, with just $20 \%$ of the course assessment focused on active learning, it could be that the two formats are similar and more akin to traditional pedagogy. Accordingly, these less-favorable reports (Ramirez and Bond 2014) could be supporting the notion that students who pursue an introductory statistics course based on traditional pedagogy are less likely to appreciate the value of statistics, and hence those students are less inclined to consider taking another statistics course. Indeed, the results from the wider published literature are quite varied in this regard, and, in some instances, counterintuitive, which could be attributed to inconsistency in instrumentation across studies and curricular design, particularly regarding what constitutes the core elements of an active learning introductory statistics course (Carlson and Winquist 2011).

The results of this study suggest that students' perceived usefulness of the introductory statistics course could play a key role in influencing their intentions to engage and pursue further studies in the discipline. Additionally, this course was a constructivist-based (or active learning) course, and, according to Fawcett 
$(2017,88)$, such a curriculum can lead to "increased student engagement with the course material" (emphasis added). Therefore, it seems reasonable to suggest that instructors give more attention to the use of data in the context of real-world problem-solving and decision-making, so that students can better appreciate the usefulness and practicality of statistics. This approach can facilitate deep and conceptual understanding and hence transferrable knowledge and skills. Moreover, the introductory course should emphasize concepts over calculations and should include multiple forms of authentic assessment.

Further research - in particular, qualitative methods such as case studies and focus groups - could prove helpful in further exploring and elucidating students' beliefs about the usefulness of the introductory statistics course as well as their intentions and decision-making regarding taking another course. Well-designed large-scale studies should be conducted to compare active learning courses to the traditional format, to determine the effect on perceived usefulness. Also, selfefficacy should be measured given its association with perceived usefulness.

While the use of a single-item measure for rating usefulness (as a proxy for perceived usefulness) may be viewed as lacking reliability and validity, it must be noted that the focus of this study was on a global rating of usefulness, given that students were asked separately about where they believe statistics will be most useful. Moreover, there is an emerging body of research supporting the use of single-item measures as having "superior predictive validity" when compared to established multi-item scales (Hoeppner et al. 2011, 9). Not to mention, the single-item measure used in the current study produced results comparable to the SATS, considered the most psychometrically sound instrument for measuring student attitudes toward statistics.

Finally, although this study used a convenience (non-probability) sample which could limit the external validity or generalizability of these findings, the sample was composed of students from three colleges, and this composition could have helped to maximize variability in terms of student characteristics. The potential for gender bias in students' perceptions of course characteristics such as "perceived value" (Young, Rush, and Shaw 2009, 10) must be considered, as well as bias associated with self-reported data.

\section{Acknowledgments}

A version of this paper was presented at the Satellite Conference of the International Association for Statistical Education (IASE) in Morocco (2017), and will be published in the conference proceedings.

\section{References}

Carlson, Kieth A., and Jennifer R. Winquist. 2011. "Evaluating an Active Learning Approach to Teaching Introductory Statistics: A Classroom 
Workbook Approach.” Journal of Statistics Education 19 (1): 1-23. http://ww2.amstat.org/publications/jse/v19n1/carlson.pdf

Engel, Joachim. 2017. "Statistical Literacy for Active Citizenship: A Call for Data Science Education.” Statistics Education Research Journal 16 (1): 44-49. https://iase-web.org/documents/SERJ/SERJ16(1)_Engel.pdf

Evans, Brian. 2007. "Student Attitudes, Conceptions, and Achievement in Introductory Undergraduate College Statistics." The Mathematics Educator 17 (2): 24-30. http://tme.journals.libs.uga.edu/index.php/tme/article/view/185

Fawcett, Lee. 2017. "The CASE Project: Evaluation of Case-Based Approaches to Learning and Teaching in Statistics Service Courses." Journal of Statistics Education 25 (2): 79-89.

GAISE College Report ASA Committee. 2016. "Guidelines for Assessment and Instruction in Statistics Education: College Report 2016."Alexandria, VA: American Statistical Association. http://www.amstat.org/asa/files/pdfs/GAISE/GaiseCollege_Full.pdf

Gal, Iddo (ed.). 2000. Adult Numeracy Development: Theory, Research, Practice. Cresskill NJ: Hampton Press.

Gundlach, Ellen, K. Andrew R. Richards, David Nelson, and Chantal LevesqueBristol. 2015. "A Comparison of Student Attitudes, Statistical Reasoning, Performance, and Perceptions for Web-Augmented Traditional, Fully Online, and Flipped Sections of a Statistical Literacy Class." Journal of Statistics Education 23 (1): 1-33. https://ww2.amstat.org/publications/jse/v23n1/gundlach.pdf

Hassad, Rossi A. 2011. "Constructivist and Behaviorist Approaches: Development and Initial Evaluation of a Teaching Practice Scale for Introductory Statistics at the College Level." Numeracy 4 (2): Article 7. https://doi.org/10.5038/1936-4660.4.2.7

. 2013. "Faculty Attitude towards Technology-Assisted Instruction for Introductory Statistics in the Context of Educational Reform." Technology Innovations in Statistics Education 7 (2): Article 10. https://escholarship.org/uc/item/9k19k2f7

- 2015. "Variability in the Teaching of Statistical Literacy: A Case of Pedagogical Dissonance." In Proceedings of the Satellite Conference of the International Association for Statistical Education (IASE). http://iaseweb.org/documents/papers/sat2015/IASE2015\%20Satellite\%2018_HASSAD. pdf

Hoeppner, Bettina B., John F. Kelly, Karen A. Urbanoski, and Valerie Slaymaker. 2011. "Comparative Utility of a Single-Item versus Multiple-Item Measure of Self-Efficacy in Predicting Relapse among Young Adults." Journal of substance abuse treatment 41 (3): 305-312. https://doi.org/10.1016/j.jsat.2011.04.005 
Nolan, Meaghan M., Tanya Beran, and Kent G. Hecker. 2012. "Surveys Assessing Students' Attitudes toward Statistics: A Systematic Review of Validity and Reliability." Statistics Education Research Journal 11 (2): 103-123. https://iase-web.org/documents/SERJ/SERJ11(2)_Nolan.pdf

Ramirez, Caroline, and Marjorie Bond. 2014. "Comparing Attitudes toward Statistics among Students Enrolled in Project-Based and Hybrid Statistics Courses." In Sustainability in Statistics Education, ed., K. Makar, B. de Sousa, and R. Gould. Proceedings of the Ninth International Conference on Teaching Statistics (ICOTS9), Flagstaff, Arizona, USA. Voorburg: International Association of Statistics Education. https://doi.org/10.1007/9783-319-38968-4_1

Rumsey, Deborah J. 2002. "Statistical Literacy as a Goal for Introductory Statistics Courses." Journal of Statistics Education 10 (3): 6-13. https://ww2.amstat.org/publications/jse/v10n3/rumsey2.html

Ryan, Richard M., and Edward L. Deci. 2000. "Self-Determination Theory and the Facilitation of Intrinsic Motivation, Social Development, and WellBeing." American Psychologist 55 (1): 68-78. http://psycnet.apa.org/record/2000-13324-007

Sabbag, Anelise Guimaraes, and Andrew Zieffler. 2015. "Assessing Learning Outcomes: An Analysis of the Goals-2 Instrument." Statistics Education Research Journal 14 (2): 93-116. http://iaseweb.org/documents/SERJ/SERJ14(2)_Sabbag.pdf

Schau, Candace, and Esma Emmioğlu. 2012. "Do Introductory Statistics Courses in the United States Improve Students' Attitudes?" Statistics Education Research Journal 11 (2): 86-94. https://www.stat.auckland.ac.nz/ iase/serj/SERJ11(2)_Schau.pdf

Sproesser, Ute, Joachim Engel, and Sebastian Kuntze. 2016. "Fostering SelfConcept and Interest for Statistics through Specific Learning Environments." Statistics Education Research Journal 15 (1): 28-54. http://iase-web.org/documents/SERJ/SERJ15(1)_Sproesser.pdf

Wallman, Katherine K. 1993. "Enhancing Statistical Literacy: Enriching our Society." Journal of the American Statistical Association 88 (421): 1-8. https://doi.org/10.1080/01621459.1993.10594283

Watkins, Ann E., Richard L. Scheaffer, and George W. Cobb. 2010. Statistics: From Data to Decision. John Wiley \& Sons, 2010. http://www.wiley.com/WileyCDA/WileyTitle/productCd-EHEP001584.html

Wigfield, Allan, Stephen Tonks, and Jacquelynne S. Eccles. 2004. "Expectancy Value Theory in Cross-Cultural Perspective." In Big Theories Revisited. Research on Sociocultural Influences on Motivation and Learning 4: 165-198. 
Young, Suzanne, Leslie Rush, and Dale Shaw. 2009. "Evaluating Gender Bias in Ratings of University Instructors' Teaching Effectiveness." International Journal for the Scholarship of Teaching and Learning 3 (2): Article 19. https://doi.org/10.20429/ijsotl.2009.030219

Wong, Kung-Teck, Timothy Teo, and Sharon Russo. 2012. "Influence of Gender and Computer Teaching Efficacy on Computer Acceptance among Malaysian Student Teachers: An Extended Technology Acceptance Model."

Australasian Journal of Educational Technology 28 (7): 1190-1207. 